Rechtsmedizin $2021 \cdot 31: 478$

https://doi.org/10.1007/s00194-021-00523-3

Online publiziert: 16. August 2021

○ Der/die Autor(en) 2021

\section{Erratum zu: Häusliche Gewalt gegen Männer - auch ein rechtsmedizinisches Problem?}

\author{
V. Kolbe · A. Büttner \\ Institut für Rechtsmedizin, Universitätsmedizin Rostock, Rostock, Deutschland
}

\section{Erratum zu:}

Rechtsmedizin 2020

https://doi.org/10.1007/s00194-020-

00382-4

Der Artikel „Häusliche Gewalt gegen Männer - auch ein rechtsmedizinisches Problem?" von V. Kolbe und A. Büttner wurde ursprünglich Online First ohne "Open Access" auf der Internetplattform des Verlags publiziert. Nach der Veröffentlichung in Bd. 30 Heft 2 pp. 88-93 hatten sich die Autoren für eine "Open Access"-Veröffentlichung entschieden. Das Urheberrecht des Artikels wurde deshalb in $\odot$ Der/die Autoren 2020 geändert. Dieser Artikel ist jetzt unter der Creative Commons Namensnennung 4.0 International Lizenz veröffentlicht, welche die Nutzung, Vervielfältigung, Bearbeitung, Verbreitung und Wiedergabe in jeglichem Medium und Format erlaubt, sofern Sie den/die ursprünglichen Autor(en) und die Quelle ordnungsgemäß nennen, einen Link zur Creative Commons Lizenz beifügen und angeben, ob Änderungen vorgenommen wurden. Die in diesem Artikel enthaltenen Bilder und sonstiges Drittmaterial unterliegen ebenfalls der genannten Creative Commons Lizenz, sofern sich aus der Abbildungslegende nichts anderes ergibt. Sofern das betreffende Material nicht unter der genannten Creative Commons Lizenz steht und die betreffende Handlung nicht nach gesetzlichen Vorschriften erlaubt ist, ist für die oben aufgeführten Weiterverwendungen des Materials die Einwilligung des jeweiligen Rechteinhabers einzuholen. Weitere Details zur Lizenz entnehmen Sie bitte der Lizenzinformation auf http://creativecommons. org/licenses/by/4.0/deed.de.

\section{Korrespondenzadresse}

\section{Kolbe}

Institut für Rechtsmedizin, Universitätsmedizin Rostock

St.-Georg-Straße 108, 18055 Rostock,

Deutschland

verena.kolbe@med.uni-rostock.de

Funding. Open Access funding enabled and organized by Projekt DEAL.

Open Access. Dieser Artikel wird unter der Creative Commons Namensnennung 4.0 International Lizenz veröffentlicht, welche die Nutzung, Vervielfältigung, Bearbeitung, Verbreitung und Wiedergabe in jeglichem Medium und Format erlaubt, sofern Sie den/die ursprünglichen Autor(en) und die Quelle ordnungsgemäß nennen, einen Link zur Creative Commons Lizenz beifügen und angeben, ob Änderungen vorgenommen wurden.

Die in diesem Artikel enthaltenen Bilder und sonstiges Drittmaterial unterliegen ebenfalls der genannten Creative Commons Lizenz, sofern sich aus der Abbildungslegende nichts anderes ergibt. Sofern das betreffende Material nicht unter der genannten Creative Commons Lizenz steht und die betreffende Handlung nicht nach gesetzlichen Vorschriften erlaubt ist, ist für die oben aufgeführten Weiterverwendungen des $\mathrm{Ma}$ terials die Einwilligung des jeweiligen Rechteinhabers einzuholen.

Weitere Details zur Lizenz entnehmen Sie bitte der Lizenzinformation auf http://creativecommons.org/ licenses/by/4.0/deed.de.

Die Online-Version des Originalartikels ist unter https://doi.org/10.1007/s00194-020-00382-4 zu finden.

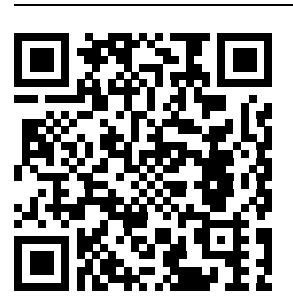

QR-Code scannen \& Beitrag online lesen 